\title{
Social Determinants of Traumatic Brain Injury in the North American Indigenous Population: A Review
}

\author{
Kaitlin J. Zeiler, Frederick A. Zeiler
}

\begin{abstract}
Objective: Given the difficult to navigate literature on social determinants in Indigenous traumatic brain injury (TBI) we wished to identify all available literature on the social determinants of health linked to TBI in the North American Indigenous populations. Methods: We performed a systematically conducted review. We searched MEDLINE, BIOSIS, EMBASE, Global Health, SCOPUS, and Cochrane Library from inception to January 2016. A two-step review process of the search results was performed, applying defined inclusion/exclusion criteria. The final group of articles had the data extracted and summarized. Results: Ten manuscripts were identified to discuss some social determinant linked to TBI in the North American Indigenous populations. Two studies were focused on Canadian populations, with the remaining 8 studies focused on populations within the United States. Six social health determinants were identified within the studies, including: Rural location (Physical Environment) in seven studies, Male gender in five studies and Female gender in one study (in the setting of interpersonal violence) (Gender), Substance use in four studies and failure to utilize personal protective equipment in one study (Personal Health Practices and Coping Skills), Interpersonal Violence in one study (Social Environment), availability of rehabilitation services in one study (Health Services), and lack of family and friend presence during meetings with healthcare professionals in one study (Social Support Network). Conclusions: To date, little literature is available on the social determinants that impact TBI in the North American Indigenous population. Further research is warranted to better determine the incidence and social determinants associated.
\end{abstract}

RÉSUMÉ: Revue portant sur les déterminants sociaux du lésion cérébrale traumatique dans la population autochtone nord-américaine. Objectif: Compte tenu de la difficulté à circonscrire les déterminants sociaux se rapportant aux traumatismes cérébraux subis au sein des populations autochtones, nous souhaitons recenser toutes les études scientifiques qui portent sur ces déterminants, et ce, dans le cas des populations autochtones d'Amérique du Nord. Méthodes: Nous avons mené une recension systématique des écrits sur ce sujet. Pour ce faire, nous avons interrogé, du début de notre recherche à janvier 2016, les bases de données suivantes : MEDLINE, BIOSIS, EMBASE, Global Health, SCOPUS et Cochrane Library. Nous avons ensuite révisé nos résultats en deux étapes à l'aide de critères d'inclusion et d'exclusion prédéfinis. Au terme de notre travail, nous avons extrait et résumé les données contenues dans ces écrits. Résultats: Nous avons identifié dix études portant sur les déterminants sociaux liés aux traumatismes cérébraux subis au sein des populations autochtones d'Amérique du Nord. Deux d'entre elles se concentraient sur des populations canadiennes ; les huit autres, sur des populations américaines. Dans ces études, six déterminants sociaux de la santé ont émergé : l'implantation rurale (Milieu physique) dans le cas de sept études ; être de sexe masculin dans le cas de cinq études ou de sexe féminin dans le cas d'une seule étude, et ce, en lien avec la violence interpersonnelle (Sexe); la consommation de drogues dans le cas de quatre études et la non-utilisation d'équipement de protection individuelle dans le cas d'une étude (Pratiques personnelles en matière de santé et Capacité d'adaptation) ; la violence interpersonnelle dans le cas d'une étude (Milieu social) ; la disponibilité de services de réadaptation dans le cas d'une étude (Services de santé) ; et finalement, dans le cas d'une étude, le manque de présence de parents et d'amis lors de consultations avec des professionnels de la santé (Réseau de soutien social). Conclusions: Jusqu'à ce jour, il n'existe que peu d'études scientifiques au sujet des déterminants sociaux qui ont un impact sur les traumatismes cérébraux subis au sein des populations autochtones d'Amérique du Nord. De plus amples recherches s'imposent donc afin de mieux cerner l'incidence de ces déterminants.

Keywords: Indigenous, TBI, brain injury, social determinants

doi:10.1017/cjn.2017.49

Can J Neurol Sci. 2017; 44: 525-531

\section{INTRODUCTION}

Traumatic brain injury (TBI) is a major source of trauma experienced in the Canadian population. ${ }^{1}$ TBI is described as an "....alteration in brain function manifest as confusion, altered level of consciousness, seizure, coma, or focal sensory or motor neurological deficit resulting from blunt or penetrating force to the head." ${ }^{2}$ Common causes TBI are motor vehicle accidents (MVAs), falls, sports-related injury, and violence. ${ }^{3}$
From the Department of Undergraduate Nursing (KJZ), University of Manitoba, Winnipeg, MB, Canada; Section of Neurosurgery (FAZ), University of Manitoba, Winnipeg, MB, Canada; Clinician Investigator Program (FAZ), University of Manitoba, Winnipeg, MB, Canada; Division of Anaesthesia (FAZ), Addenbrooke's Hospital, University of Cambridge, Cambridge, United Kingdom.

Received September 29, 2016. Final Revisions Submitted February 13, 2017. Date of Acceptance March 6, 2017.

Correspondence to: Frederick A. Zeiler, Department of Surgery, Rady Faculty of Health Sciences, University of Manitoba, Winnipeg, MB, Canada R3A1R9.

Email: umzeiler@myumanitoba.ca 
TBI is the most frequent source of accidental death and injury and disability in Canada, the United States, and the world. ${ }^{4}$ In the United States, approximately 1.7 million people suffer a TBI per year, resulting in 270,000 hospitalizations and 52,000 deaths. ${ }^{5}$ Canadian epidemiology describes approximately 23,000 affiliated hospitalizations from TBI and $8 \%$ resulting in death. ${ }^{4,5}$

Numerous epidemiological studies have been conducted in the general trauma and TBI literature to define the demographic and social features linked to developing TBI and outcome. All health care providers would benefit from a better understanding of this phenomenon and what may precipitate these injuries. Because of the considerable number of indigenous people afflicted with this injury process, ${ }^{6}$ it is important to understand what, if anything, may place this population at risk as a means to guide education and care in this area. Additionally, despite the large indigenous population within North America, there is minimal research in the area of TBI and specifically any social determinants related to TBI.

TBI is a common injury in the general population of North America, yet is noted to affect the indigenous population of North America at a greater prevalence, with 27/100,000 TBI-related deaths versus $18 / 100,000$ in the indigenous and general populations, respectively. ${ }^{6,7}$

Although the TBI risk in indigenous people has been identified, Strayer et $\mathrm{al}^{8}$ note there are few studies that discuss the social determinants that may affect indigenous people and place them at higher risk to suffer a TBI. The goal of this systematically conducted review was to perform an extensive outline of the available literature to define the social determinants linked to TBI within the North American indigenous population.

\section{MeTHODS}

We performed a review using the systematic review principles outlined Higgins and Green ${ }^{9}$ in the Cochrane Handbook of Systematic Reviews. We reported the results of this review following the principles outlined in the preferred reporting items in systematic reviews and meta-analysis guidelines. ${ }^{10}$

\section{Search Question, Population, and Inclusion and Exclusion Criteria}

The question posed for the review was: What are the social determinants of health associated with TBI in North American indigenous peoples?

The definition used for the "social determinants of health" is that provided by Health Canada, ${ }^{11}$ which includes: income and social status, social support networks, education and literacy, employment/working conditions, social environments, physical environments, personal health practices and coping skills, healthy child development, biology and genetic endowment, health services, gender, and culture. The determinant of culture was a set variable within our review because the goal was to focus on TBI determinants in indigenous populations only. All studies of any design type were included. The reason for an all-inclusive search was based on the small number of relevant results identified during a preliminary search of MEDLINE.

The primary outcome measure of interest was the documentation of social health determinants linked to TBI in North American indigenous populations. The secondary outcome measure was documented incidence rates of TBI in North American indigenous populations.

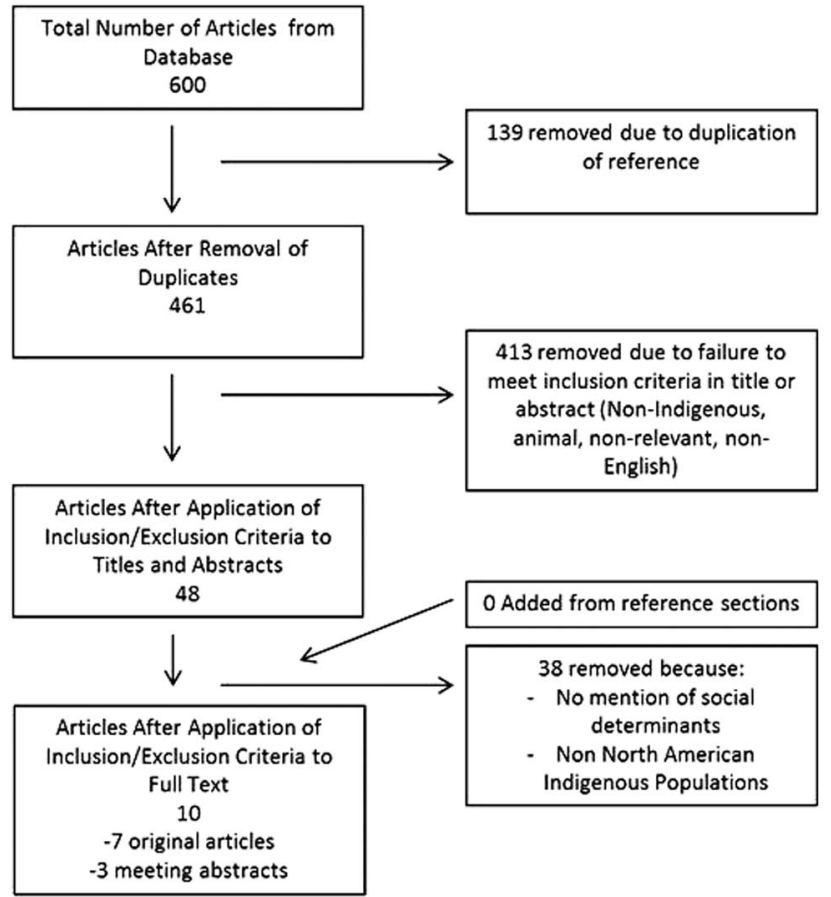

Figure 1: Flow diagram of search results

Inclusion criteria were all studies, any study design, human subjects only, any age category of subjects, indigenous populations only, the documentation of social determinants linked to TBI in indigenous populations, and North American (Canada and United States only) locations of study subjects.

Exclusion criteria were non-English studies, studies failing to document the association of social determinants of health to TBI, studies not focused on indigenous populations, and studies with subjects not from Canada or the United States. We specifically excluded Mexico from the analysis given the complexities in identifying Mexican indigenous populations. There were no dedicated English language studies on TBI from Mexico that focused on indigenous populations. Furthermore, studies originating from the United States did not differentiate Hispanic from Mexican indigenous populations, lumping all Hispanic populations into one category.

\section{Search Strategy}

MEDLINE, BIOSIS, EMBASE, Global Health, SCOPUS, and the Cochrane Library from inception to January 2016 were searched using individualized search strategies for each database. The search strategy for MEDLINE can be seen in Appendix A, with a similar search strategy used for the other databases.

\section{Study Selection}

A two-step review of all articles returned by the search strategy was performed. First, each search result was screened by titles and abstract to decide if they met the inclusion criteria. Second, full text of the chosen articles was then assessed to confirm if they met the inclusion criteria and that the primary outcome was reported in the study. Finally, reference lists of relevant articles were hand 


\section{Table 1: Canadian study characteristics}

\begin{tabular}{|c|c|c|c|c|c|c|}
\hline Reference & $\begin{array}{l}\text { Country of study/ } \\
\text { region }\end{array}$ & $\begin{array}{l}\text { Time frame } \\
\text { of data } \\
\text { acquisition }\end{array}$ & $\begin{array}{l}\text { Number of } \\
\text { indigenous } \\
\text { TBI patients }\end{array}$ & Etiology of TBI & Comparison group & $\begin{array}{l}\text { TBI-associated social } \\
\text { determinants of health }\end{array}$ \\
\hline $\begin{array}{l}\text { Blackmer et al, } \\
1999\end{array}$ & $\begin{array}{l}\text { Canada: } \\
\text { Saskatchewan }\end{array}$ & 1994-1997 & $18 / 70(25.7 \%)$ & $\begin{array}{l}\text { 1. MVA }(8 / 18) \\
\text { 2. Fall }(5 / 18) \\
\text { 3. Assault }(1 / 18) \\
\text { 4. Other }(4 / 18)\end{array}$ & $\begin{array}{l}\text { Yes: Nonindigenous North } \\
\text { Americans from same region }\end{array}$ & $\begin{array}{l}\text { 1. Male } \\
\text { 2. Alcohol/drugs }(\mathrm{p}<0.0001)^{*} \\
\text { 3. Rural setting }(\mathrm{p}<0.0001)^{*} \\
\text { 4. Family availability } \\
\quad(\mathrm{p}<0.0001)^{*} \\
\text { 5. Available rehabilitation } \\
\quad \text { services }(\mathrm{p}<0.001)^{*}\end{array}$ \\
\hline $\begin{array}{l}\text { Dudley et al, } \\
2012\end{array}$ & Canada: Quebec & $2005-2010$ & Unknown & Unknown & Yes: general population & $\begin{array}{l}\text { 1. Geographic region: northern } \\
\text { community }(\mathrm{p}<0.001)^{*}\end{array}$ \\
\hline
\end{tabular}

*p values represent statistically significant difference between indigenous and comparison groups.

$\mathrm{TBI}=$ traumatic brain injury; MVA = motor vehicle accident.

searched to see if any papers were missed by the previously outlined database search. Figure 1 displays the flow diagram of article selection.

\section{Data Collection}

Data were extracted from the final selected articles and are tabulated in Tables 1 and 2. Data fields included country of study/ region, time frame of data acquisition, number of indigenous TBI patients, etiology of TBI, comparison groups, and TBI-associated social determinants of health.

\section{Statistics}

Because the goal of this study was to provide a systematically conducted review of the literature surrounding social determinants and TBI in the North American indigenous populations, only a description of the available literature was provided. No statistical analysis was performed.

\section{Results}

\section{General Study Demographics}

Figure 1 outlines the search strategy and process of final article selection. The search strategy identified 600 results. A total of 139 were identified as duplicate results, leaving a total of 461 unique results to review during the first phase of the filtering process. During review of the abstract and title of these 461 results, 48 met the inclusion/exclusion criteria. Upon review of the full manuscripts of these 48 articles, 10 met the inclusion/exclusion criteria. The 38 articles excluded were done so because they were either not focused on North American indigenous populations or they had no mention of social determinants linked to TBI. Thus, overall, 10 manuscripts were identified with some mention of associated social health determinants linked to TBI in North American indigenous populations.

Of the ten studies included in the final review, only two were from Canada ${ }^{6,12}$ and eight were from the United States. . $^{3,7,8,13-17}$ The Canadian-based studies focused on indigenous peoples in Saskatchewan ${ }^{6}$ and Quebec. ${ }^{12}$ The remaining US-based articles focused on the general population in four papers, the Alaskan population in three, and the Arizona population in two. The data for the Canadian and US-based studies can be seen in Tables 1 and 2 , respectively.
The majority of studies compared the rates and causes of TBI to the general population in their respective areas.

The incidence of TBI in the indigenous populations varied significantly, as seen in Tables 1 and 2 . The highest recorded incidence was $25.7 \%^{6}$ within a single-center study. The overall typical population based incidence of TBI deaths in the indigenous population was approximately 27 per 100,000 compared with $18.4 / 100,000$ in the entire population. ${ }^{3}$

The etiology of TBI was fairly consistent across studies, with MVA, falls, and assaults leading to the number one, two, and three causes of TBI, respectively., ${ }^{3,13}$ Assaults and firearm-related causes of TBI and TBI related mortality were disproportionately represented as causes of TBI, when compared with general population data. ${ }^{3,15}$

\section{Associated Social Determinants Identified}

There are 11 social determinants of health (excluding culture) defined by Health Canada which include; Income and social status, social support networks, education and literacy, employment/ working conditions, social environments, physical environments, personal health practices and coping skills, healthy child developments, biology and genetic endowment, health services, and gender. The US Centers for Disease Control and Prevention (CDC) has published its own version of health determinants, for which it defines only five: economic stability, education, social/community context, health/health care, and neighborhood/built environment. Despite our review focusing on both Canadian and US-based literature, we avoided using the CDC determinants of health given that the Health Canada determinants were much more detailed and allowed for a more comprehensive assessment of contributing health determinants in North American TBI in indigenous populations.

Throughout this review, only six social health determinants have been associated to TBI in the North American indigenous populations: rural location (physical environment) in seven studies, male gender in five studies and female gender in one study (in the setting of interpersonal violence) (gender), substance use in four studies and failure to use personal protective equipment in one study (personal health practices and coping skills), interpersonal violence in one study (social environment), availability of rehabilitation services in one study (health services), and lack of family and friend presence during meetings with health care professionals in one study (social support network). 
Table 2: US study characteristics

\begin{tabular}{|c|c|c|c|c|c|c|}
\hline Reference & $\begin{array}{l}\text { Country of } \\
\text { study/region }\end{array}$ & $\begin{array}{l}\text { Time frame of } \\
\text { data acquisition }\end{array}$ & $\begin{array}{c}\text { Number of } \\
\text { indigenous TBI } \\
\text { patients }\end{array}$ & Etiology of TBI & Comparison group & $\begin{array}{l}\text { TBI-associated social } \\
\text { determinants of health }\end{array}$ \\
\hline $\begin{array}{l}\text { Adekoya et al, } \\
\quad 2002\end{array}$ & United States & 1989-1998 & $\begin{array}{l}5824 \text { total } \\
27.2 \text { per } 100,000^{*}\end{array}$ & $\begin{array}{l}\text { 1. MVA } \\
\text { 2. Falls } \\
\text { 3. Firearms } \\
\text { 4. Other/unknown }\end{array}$ & Yes: white. black, other & 1. Males $\dagger$ \\
\hline $\begin{array}{l}\text { Coronado et al, } \\
2011\end{array}$ & United States & $1997-2007$ & $\begin{array}{l}6803 \text { total } \\
27.3 \text { per } 100,000^{*}\end{array}$ & $\begin{array}{l}\text { 1. MVA } \\
\text { 2. Falls } \\
\text { 3. Firearm } \\
\text { 4. Other/unknown }\end{array}$ & $\begin{array}{l}\text { Yes: white, black, Hispanic, } \\
\text { other/unknown }\end{array}$ & $\begin{array}{l}\text { 1. Males } \dagger \\
\text { 2. Physical environment } \dagger\end{array}$ \\
\hline $\begin{array}{l}\text { Rutland-Brown } \\
\text { et al, } 2005\end{array}$ & $\begin{array}{l}\text { United States } \\
\text { (13 states) }\end{array}$ & 1997-1999 & $910 / 60,710(1.5 \%)$ & $\begin{array}{l}\text { 1. MVA: } 41 \% \\
\text { 2. Falls: } 13 \% \\
\text { 3. Assaults: } 21 \% \\
\text { 4. Other: } 20 \% \\
\text { 5. Unknown: } 5.2 \%\end{array}$ & Yes: white, black, Asian races & $\begin{array}{l}\text { 1. Alcohol: } \mathrm{p}<0.0001 \ddagger \\
\text { 2. Protective equipment: } \\
\mathrm{p}<0.0001 \ddagger \\
\text { 3. Geographic region: on } \\
\text { reserve }\end{array}$ \\
\hline CDC, 2002 & $\begin{array}{l}\text { United States: } \\
\text { Alaska }\end{array}$ & 1992-1996 & 4491 total & $\begin{array}{l}\text { 1. MVA: } 24 \% \\
\text { 2. Assaults: } 17 \% \\
\text { 3. Falls: } 16 \%\end{array}$ & no & $\begin{array}{l}\text { 1. Male } \dagger \\
\text { 2. Geographic region: } \\
\text { Alaska } \dagger\end{array}$ \\
\hline $\begin{array}{l}\text { Linton et al, } \\
2015\end{array}$ & $\begin{array}{l}\text { United States: } \\
\text { Arizona }\end{array}$ & $2008-2010$ & Unknown & $\begin{array}{l}\text { 1. IPV } \\
\text { 2. Other }\end{array}$ & $\begin{array}{l}\text { Yes: white, black, Asian, other, } \\
\text { race missing from data }\end{array}$ & $\begin{array}{l}\text { 1. Alcohol }(\mathrm{p}=0.002) \ddagger \\
\text { 2. Rural } \\
\text { 3. Female (due to IPV) }\end{array}$ \\
\hline Linton, 2014 & $\begin{array}{l}\text { United States: } \\
\text { Arizona }\end{array}$ & $2008-2010$ & $1763 / 18,868(1.5 \%)$ & $\begin{array}{l}\text { 1. MVA: } 693 / \\
1763(39.3 \%) \\
\text { 2. Falls: } 362 / 1763 \\
(20.5 \%) \\
\text { 3. Violence: } 652 / \\
1763(37.0 \%) \\
\text { 4. Other: } 56 / 1763 \\
(31.8 \%)\end{array}$ & Yes: white, black, Asian, other & 1. Males $(\mathrm{p}<0.01) \ddagger$ \\
\hline $\begin{array}{l}\text { Strayer et al, } \\
2013\end{array}$ & $\begin{array}{l}\text { United States: } \\
\text { Alaska }\end{array}$ & 2004-2008 & Unknown & $\begin{array}{l}\text { 1. MVA } \\
\text { 2. Falls } \\
\text { 3. Assaults }\end{array}$ & Yes: non-natives & $\begin{array}{l}\text { 1. Alcohol } \dagger \\
\text { 2. Geographic region-rural } \dagger\end{array}$ \\
\hline $\begin{array}{c}\text { Strayer et al, } \\
2014\end{array}$ & $\begin{array}{l}\text { United States: } \\
\text { Alaska }\end{array}$ & $2007-2011$ & 176 per 100,000 & Unknown & Yes: non-natives & 1. Geographic region $\dagger$ \\
\hline
\end{tabular}

*The rates quoted are TBI r-related deaths and not general incidence of TBI.

$\dagger$ Unclear within parent manuscript/abstract whether the determinant report reached statistical significance.

$\ddagger \mathrm{p}$ values represent statistically significant difference between indigenous and comparison group.

MVA $=$ motor vehicle accident; TBI $=$ traumatic brain injury.

The top three social determinants (based on the number of studies describing these determinants) linked to TBI in North American indigenous populations are physical environment (seven studies), gender (six studies), and personal health practices and coping skills (five studies). Summary of the individual study characteristics can be seen in Tables 1 and 2, with the health determinants identified in each study listed in the last column of both tables.

Three studies documented a statistically significant difference between indigenous and nonindigenous comparison groups, with reference to social determinants of health linked to TBI. These studies identified a significant difference in the rates of all of the previously mentioned social determinants, except male gender. This is exemplified within the Canadian-based studies, where indigenous TBI patients displayed higher substance use (13/18 vs $5 / 52 ; \mathrm{p}<0.0001)$, rural/reserve living environment $(14 / 18$ vs $29 / 52$ rural/reserve; $p<0.0001)$, less family availability ( 0.33 vs 1.04 mean family conferences; $\mathrm{p}<0.0001$ ), and less rehabilitation services (8/18 vs $47 / 52$ patients with resources available; $\mathrm{p}<0.0001) .{ }^{6}$ Similar trends are found within the US-based studies
(Tables 1 and 2, including the parent papers referenced within this review, show details on the absolute numbers).

\section{Discussion}

All-cause trauma is a major contributor to death within the indigenous populations of North America. ${ }^{18}$ Population-wide studies of mortality indicate that indigenous people have the highest mortality rate within the following demographic categories: race/ethnicity, falls, and MVAs. ${ }^{3}$ Similarly, Dudley et al ${ }^{12}$ discuss the indigenous population of Quebec reported a rate of TBI of four times the general Canadian population.

Comparatively, the indigenous population suffers TBI at higher incidence than the general population, as Rutland-Brown et $\mathrm{al}^{7}$ described. This population suffers TBI at a rate of 71.5/100,000 compared with 70.9/100,000 for all ages. ${ }^{7}$ This number increases greatly for young adults in the 20- to 44-years of age range, which noted a $30 \%$ increase of TBI in the indigenous population compared with the general population. ${ }^{7}$ Despite this, there has been little research done in the area of social determinants of TBI, specifically in the indigenous populations. On a Canadian 
province-to-province basis, Quebec and Saskatchewan were the only provinces with published data on TBI in the indigenous populations. This simple lack of available literature sparked this review.

\section{Trends Identified With the Review}

Through completing this review, the following social determinants of health have been linked to TBI in the North American indigenous populations: physical environment, gender, personal health practices and coping skills, social environment, health services, and social support network. These determinants were highlighted through common themes of suffering from substance abuse, violence, living in a rural setting with limited access to health care, and being involved in a motor vehicle collision.

\section{Physical Environment}

Societal and health inequalities on many First Nations lands are excessive, and living conditions are substandard. ${ }^{19}$ Socioeconomic status (SES) and its direct implications with respect to TBI are not well documented; however, the indigenous population is known to suffer greater health disparities than the general population. ${ }^{20}$ Therefore, it can be extrapolated that there exists a potential indirect link between poor SES and TBI, with poor SES manifesting as a function of social factors such as increased risk-taking behavior, social dysfunction, and lack of educational resources. ${ }^{21}$

For example, approximately $35 \%$ of indigenous people in Manitoba live on a reservation. ${ }^{22}$ This is just a single Canadian example of the remote physical environment in which some North American indigenous people live. Geographic location was described as a factor contributing to TBI in this population; such factors contributing to TBI were rural locations having decreased access to health services, ${ }^{3}$ varied governance regarding seat belt laws on reservations, ${ }^{7}$ and increased substance abuse on First Nations. ${ }^{22}$ Lasry et $\mathrm{al}^{23}$ discussed that living in reservation-based rural communities exposes these populations to increased risk of acquiring injuries resulting from a lack of infrastructure (unpaved roads). This promotes the use of alternative modes of transportation including all-terrain vehicles and snowmobiles, both of which carry the potential of higher incidence of TBI given lack of protection to their operators. ${ }^{23}$

\section{Gender}

Gender has displayed an overwhelming influence in TBI occurrence and was identified as a significant social determinant linked to TBI in the indigenous population within this review. Male gender was attributed to $41 / 100,000$ TBI-related deaths (73\% of all indigenous TBI-related deaths) in the indigenous populations versus $14 / 100,000$ (27\% of all indigenous TBI-related deaths) in indigenous females. ${ }^{3}$ In comparison, the incidence of TBI-related deaths within the white, non-Hispanic, North American population has been reported with rates of up to $29 / 100,000$ (72\% of TBI deaths in the white population), according to the CDC. ${ }^{3}$ Furthermore, the rate of TBI-related death in white, non-Hispanic women is also lower than those rates reported for indigenous women, with 9.6/100,000 reported ( $28 \%$ of TBI deaths in the white population). ${ }^{3}$

Through both the Canadian and US-based studies, almost every paper linked male gender to TBI in indigenous populations. This link can potentially be attributed to an increase in risk-taking behavior and specific personal health practices, such as alcohol abuse. Female gender was linked only to an increased risk of TBI within the indigenous population in reference to interpersonal/family-related violence. ${ }^{16}$

\section{Personal Health Practices}

Personal health practices are described as a determinant of health in Canada. ${ }^{11}$ Frequently described health practices linked to TBI within the indigenous population were substance abuse and risk-taking behaviors. ${ }^{6,7}$ Other health determinants having an impact in conjunction with personal health practices were geographical location (usually rural) and violence resulting in assault, which is linked to social environment. ${ }^{7,16}$

Alcohol use was associated in the indigenous population when suffering a TBI. ${ }^{6,7}$ Blackmer et $\mathrm{al}^{6}$ discuss that, in Canada, the indigenous population who had consumed alcohol prior to suffering a TBI was $83 \%$ compared with approximately $10 \%$ in the general population $(\mathrm{p}<0.0001)$. Further, within the indigenous population, motor vehicle collisions were the highest cause of TBI. ${ }^{14,24}$ These incidents were closely linked with alcohol use in this population. ${ }^{6}$ Lack of protective equipment use such as seat belts in motor vehicles was also described as a contributing factor in this population related to acquiring a TBI. ${ }^{7}$ This was found to be prevalent in combination with alcohol use; therefore, it could be deduced that failure to use safety restraints was related to alcohol use. These findings are notable because they display collective issues that can be seen across generations. ${ }^{25}$

\section{Social Environment}

Interpersonal violence was noted to be an overrepresented mechanism of injury in the younger indigenous populations. ${ }^{16}$ Linton et $\mathrm{al}^{15}$ noted women, more frequently than men, were victims of this type of violence resulting in TBI (odds ratio 1.35, $\mathrm{p}<0.001$ ). Men (47\%) and women (32\%) of indigenous decent were both more likely than Caucasian men and women, ( $21 \%$ and $8.5 \%$, respectively) to experience TBI with a violent etiology $(\mathrm{chi}=237.4$ for females, chi $=445.5$ for females; $\mathrm{p}<0.01) .{ }^{16}$ As discussed previously, the rationale of why this injury pattern is so prevalent in this community seems to have many factors that seem to involve a large number of variables, ${ }^{23}$ including many social determinants of health such as SES, rural locations, culture, and personal experiences. ${ }^{23}$

\section{Health Services and Social Supports}

With respect to health services and social supports, Blackmer et $\mathrm{al}^{6}$ explain there exists a lack of rehabilitation services and formalized care for those indigenous people suffering from TBI. Isolated communities' lack many services required to assist patients after TBI, especially if the person has suffered a moderate or severe TBI. Services people may require include outpatient physical therapy, occupational therapy, and long-term care. ${ }^{23}$ With the lack of available supports, family members often become burdened with caring for these individuals alone, which can in turn cause a host of issues (financial, physical, and mental) for both the patient and family caregiver(s) ${ }^{20}$

An example of this within Canada would be Manitoba's indigenous population, who are known to suffer greater health disparities compared with the general population. ${ }^{26}$ Many individuals of this culture suffer marginalization resulting from assimilation, loss of land, forced attendance of residential schools, and subsequent abuse and neglect that has precipitated negative 
coping behaviors such as drug and alcohol abuse. ${ }^{21}$ These post-assimilation factors are extremely comprehensive, as they are known to contribute to poorer health, lower socioeconomic statuses, and social disparities across the indigenous culture. ${ }^{19}$

\section{Missing Trends}

Despite the associated health determinants identified within this review, we know from epidemiological studies of general health in indigenous communities that other determinants such as lack of education within this population, low employment rates, and child health ${ }^{27}$ are linked to health disparities. It is unclear why these particular social determinants of health have not been identified as determinants linked to TBI in the North American indigenous populations.

Health Canada ${ }^{27,28}$ reports that First Nations people are less likely to complete a high school education than their peers from other cultural backgrounds. There is an immense impact that education, or lack thereof, can have on several factors, including SES, health awareness, and greater access to resources. ${ }^{27,28}$

Lack of education, along with other influences such as low employment rates, has a direct link to SES. ${ }^{29}$ SES affects health and well-being in many ways, and having low SES places an individual at a greater disadvantage, which only amplifies the inequities indigenous peoples already face. SES affects health status, poverty, nutrition, and mental health and illness, which all continue to have consequences in a social context. ${ }^{29}$ King et $\mathrm{al}^{20}$ explain the link between SES and substance addiction, which in turn places individuals at increased risk for injury.

Ross et $\mathrm{al}^{21}$ highlight that indigenous people who were subjected to residential school environments were noted to have an increased risk of alcohol abuse compared with individuals who did not attend residential schooling. This trauma is shown to have intergenerational effects, which places not only survivors, but also their children, at risk for many health disparities, including TBI. Despite the abundance of research into the detrimental effects residential schools, there continues to be a lack of epidemiological research into the secondary effects such as risk of TBI.

\section{Implications and Future Directions}

TBI is described as a considerable source of morbidity and mortality in the Indigenous population of North America. ${ }^{15}$ Within this review, the lack of literature noting specific social determinants related to TBI was apparent. Strategies that may assist in addressing this issue are described further.

Community is known to be extremely important and connected to health and well-being in the indigenous population. ${ }^{20}$ Interventions should be focused on collaboration with community organizations and be culturally guided. Collaborations with elders and respected members could help to bridge the gap between health care workers and individuals of the community. Ross et $\mathrm{al}^{21}$ noted that failure to involve the wider indigenous population in the management and planning surrounding health issues within its own communities may lead to barriers in the understanding and acceptance of care. Advocating for indigenous health will facilitate improvement in resources, social programs, and access, especially in remote communities. ${ }^{25}$ Advocating for this community on a governmental level can address the immense impact social problems, such as low SES, have in regard to health disparities such as TBI. ${ }^{25}$ Injury prevention programs involving multidisciplinary teams and community groups, especially in rural and reserve areas, may strengthen bonds and empower communities to adopt knowledge to prevent injuries and prevent TBI. $^{20}$

In regard to culture and how imperative it is to include in this population's health care, King et $\mathrm{al}^{20}$ explain that indigenous peoples see personal health as physical, mental, emotional, and spiritual health. The "western" medicine approach focuses mainly on illness and treatment. Care needs to focus on not only illnesses and treatment (i.e. treatment for substance abuse), but also to incorporate culture and community, assisting in understanding the effects these social determinants have on their culture in respect to physical, mental, emotional, and spiritual health. ${ }^{20}$ Traditional healing practices such as healing circles and smudging ceremonies are important rituals in the indigenous community. Thus, it is important to incorporate these cultural practices, which address the mental and emotional aspect of healing in the indigenous culture. ${ }^{24}$

If we are to engage the indigenous community in health promotion and provide culturally competent care, we also need to reflect on our own beliefs to provide unbiased health care to ensure we are meeting the needs of our clients. Blackmer et $\mathrm{al}^{6}$ explain that indigenous people were offered family conferences less often, in addition to receiving less postdischarge care after TBI. ${ }^{6}$ This identifies a disturbing statistic and reinforces the need for improved communication and collaboration between health care providers and cultural liaisons in the hospital setting. ${ }^{6}$

Alcohol and substance abuse is prevalent in the indigenous communities. $^{21}$ Subsequently, alcohol is a major contributing factor in acquiring a TBI because it is related to the incidence of MVSs, violence, and lack of protective equipment use. ${ }^{3,16}$

Collaboration with community elders and the community to develop substance abuse programs and address addiction and its risk factors would benefit this population immensely to reduce the risk of suffering a TBI. ${ }^{6}$ Improvement in community resources to assist in education for children, adolescents, and young adults to develop both healthy living styles and disease prevention techniques could potentially assist younger generations in improving health practices and coping skills. Additionally, this may reduce the risk of alcohol addiction and its consequences. Treatment programs for addiction located within the community would assist the indigenous peoples, especially those living in rural and on reserve areas, because there is a current lack of accessibility to such treatment facilities. ${ }^{16}$

Despite the defined social determinants described within this review, the underlying social, cultural, and physical environment issues that indigenous people have been, and continue to be subjected to, cannot be overemphasized. ${ }^{25}$ These issues need addressing through promotion of healthy public policy and social justice because it is clear from this review that there are significant disparities between the indigenous and general North American populations. Health promotion is key to assist the indigenous people in combating all disease and preventing illness in the future. ${ }^{30}$ Working with the communities to develop strategies that would effectively communicate the importance of prevention and understand the devastating effects TBI can have would be beneficial. $^{20}$ With respect to holistic health, strategies that promote mental health and enact positive coping strategies to deal with the past effects of trauma could be helpful on an individual as well as community level. ${ }^{20}$ Interventions such as counseling groups incorporating indigenous culture/practices may have a 
positive impact on the negative coping skills that some have adopted to deal with previous trauma. ${ }^{23}$

\section{Conclusions}

To date, limited literature is available on the social determinants that affect TBI in the North American indigenous populations. Further research is warranted to better determine the incidence and social determinants associated with TBI.

\section{ACKNOWLEDGMENTS AND Funding}

This work was made possible through salary support through the University of Manitoba Clinician Investigator Program, Royal College of Surgeons - Harry S. Morton Traveling Fellowship in Surgery, R. Samuel McLaughlin Research and Education Award, the Manitoba Medical Service Foundation, and the University of Manitoba - Faculty of Medicine Dean's Fellowship Fund.

\section{Disclosures}

FZ has received salary support for dedicated research time, during which this project was partially completed. Such salary support came from the University of Manitoba Clinician Investigator Program, Royal College of Surgeons - Harry S. Morton Traveling Fellowship in Surgery, R. Samuel McLaughlin Research and Education Award, the Manitoba Medical Service Foundation, and the University of Manitoba - Faculty of Medicine Dean's Fellowship Fund. KZ does not have anything to disclose.

\section{Statement of Authorship}

FAZ was involved in study design, search execution, data analysis, manuscript editing, and project supervision. KJZ was involved in study design, search execution, data analysis, and manuscript writing.

\section{Supplementary Material}

To view supplementary material for this article, please visit https://doi.org/10.1017/cjn.2017.49

\section{REFERENCES}

1. Kirkwood M, Yeates K. Mild traumatic brain injury in children and adolescents: from basic science to clinical management. New York, NY: Guilford Press; 2012.

2. Bruns J, Hauser WA. The epidemiology of traumatic brain injury: a review. Epilepsia. 2003;44:2-10.

3. Coronado VG, Xu L, Basavaraju SV, et al. Surveillance for traumatic brain injury related deaths-United States 1997-2007. Centers for Disease Control and Prevention. MMWR Surveill Summ. 2011;60:1-32.

4. Fu TS, Jing R, McFaull SR, Cusimano MD. Recent trends in hospitalization and in-hospital mortality associated with traumatic brain injury in Canada: a nation-wide, population based study. J Trauma Acute Care Surg. 2015;79:449-55.

5. Lump D. Managing patients with severe traumatic brain injury. Nursing. 2014;44:30-7.

6. Blackmer J, Marshall SC. A comparison of traumatic brain injury in the Saskatchewan native North American and non-native North American populations. Brain Inj. 1999;13:627-35.

7. Rutland-Brown W, Wallace LJD, Faul MD, Langlois JA. Traumatic brain injury hospitalizations among American Indians/Alaska natives. J Head Trauma Rehabil. 2005;20:205-14.
8. Strayer H, Hodges J. Traumatic brain injuries of Alaska Native people: trends and disparities from 1991-2011 (abstract). J Head Trauma Rehabil. 2013;28:40.

9. Higgins JPT, Green S. editors. Cochrane handbook for systematic reviews of interventions, version 5.1.0. Available at: http:// handbook.cochrane.org.

10. Moher D, Liberati A, Tetzlaff J, et al. Preferred reporting items for systematic reviews and meta-analysis: the PRISMA statement. Ann Intern Med. 2009;151:264-9.

11. Public Health Agency of Canada. What determines health? Available at: http://www.phac-aspc.gc.ca/ph-sp/determinants/ index-eng.php\#determinants.

12. Dudley RW, Faez M, Maleki M, Marcoux J. Comparison of traumatic brain injury between aboriginal communities of Northern Quebec and the general Quebec population (abstract). Can J Neurol Sci. 2012;39(suppl. 3):S20.

13. Adekoya N, Thurman DJ, White DD, Webb KW. Surveillance for traumatic brain injury deaths-United States, 1989-1998. Centers for Disease Control and Prevention. MMWR Surveill Summ. 2002;51:1-14.

14. Centers for Disease Control and Prevention. Traumatic brain injury among American Indians/Alaska Natives-United States, 1992-1996. MMWR Surveill Summ. 2002;51:303-5.

15. Linton KF. Interpersonal violence and traumatic brain injuries among Native Americans and women. Brain Inj. 2015;29:639-43.

16. Linton KF, Kim BJ. Traumatic brain injury as a result of violence in Native American and black communities spanning from childhood to older adulthood. Brain Inj. 2014;28:1076-81.

17. Strayer H, Lucas MP. Whose head hurts in Alaska? TBI trends and disparities. Brain Inj. 2014;28:566.

18. Hoopes MJ, Dankovchik J, Weiser T, et al. Uncovering a missing demographic in trauma registries: epidemiology of trauma among American Indians and Alaska Natives in Washington State. Inj Prevent. 2015;21:335-43.

19. Richmond CAM. Narratives of social support and health in aboriginal communities. Can J Public Health. 2007;98:347-51.

20. King M, Smith A, Gracey M. Indigenous health part 2: the underlying causes of the health gap. Lancet. 2009;374:76-85.

21. Ross A, Dion J, Cantinotti M, Collin-Vézina D, Paquette L. Impact of residential schooling and of child abuse on substance use problem in Indigenous peoples. Addict Behav. 2015;51: 184-192.

22. Hallett B, Secretariat Department of Aboriginal Affairs and Development in Manitoba. Aboriginal people in Manitoba. Ottawa, ON: Service Canada; 2006. Available at http://www.gov.mb.ca/ $\mathrm{imr} / \mathrm{ir} /$ resources/pubs/abpeoplembweb.pdf.

23. Lasry OJ, Carlin R, Torrie J. The epidemiology of traumatic brain injury in the Cree communities of Eeyou Istchee. 2015. Available at: http://www.creehealth.org/sites/default/files/TBI_CBHSSJB report_OL.pdf.

24. Whitfield HW, Lloyd R. American Indians/Native Alaskans with traumatic brain injury. Rehabil Counsel Bull. 2008;51:190-192.

25. Mahoney D, Jones EJ.. Social determinants of health in nursing education, research and health policy. Nurs Sci Q. 2013;26:280-4.

26. Stats Canada. Aboriginal peoples in Canada: First Nations people, Métis and Inuit. 2015. Available at: https://www12.statcan.gc.ca/ nhs-enm/2011/as-sa/99-011-x/99-011-x2011001-eng.cfm

27. Health Canada. Statistical profile on the health of First Nations in Canada: determinants of health, 2006 to 2010. First Nations and Inuit Health. 2014. Available at: http://www.hc-sc.gc.ca/ fniah-spnia/pubs/aborig-autoch/2010-stats-profil-determinants/ index-eng.php.

28. Health Canada. First Nations and Inuit health: Health status of First Nations on reserve in Atlantic Canada (HC Publication No. 140540). 2014. Retrieved from: First_Nations_Health_Status Report_ENG.pdf.

29. Loppie RC, Wien F. Health inequalities and the social determinants of aboriginal peoples' health. Prince George, BC: National Collaborating Centre for Aboriginal Health; 2009.

30. Kolahdooz F, Nader F, Yi KJ, Sharma S. Understanding the social determinants of health among indigenous Canadians: priorities for health promotion policies and actions. Glob Health Action. 2015;8:27968. 